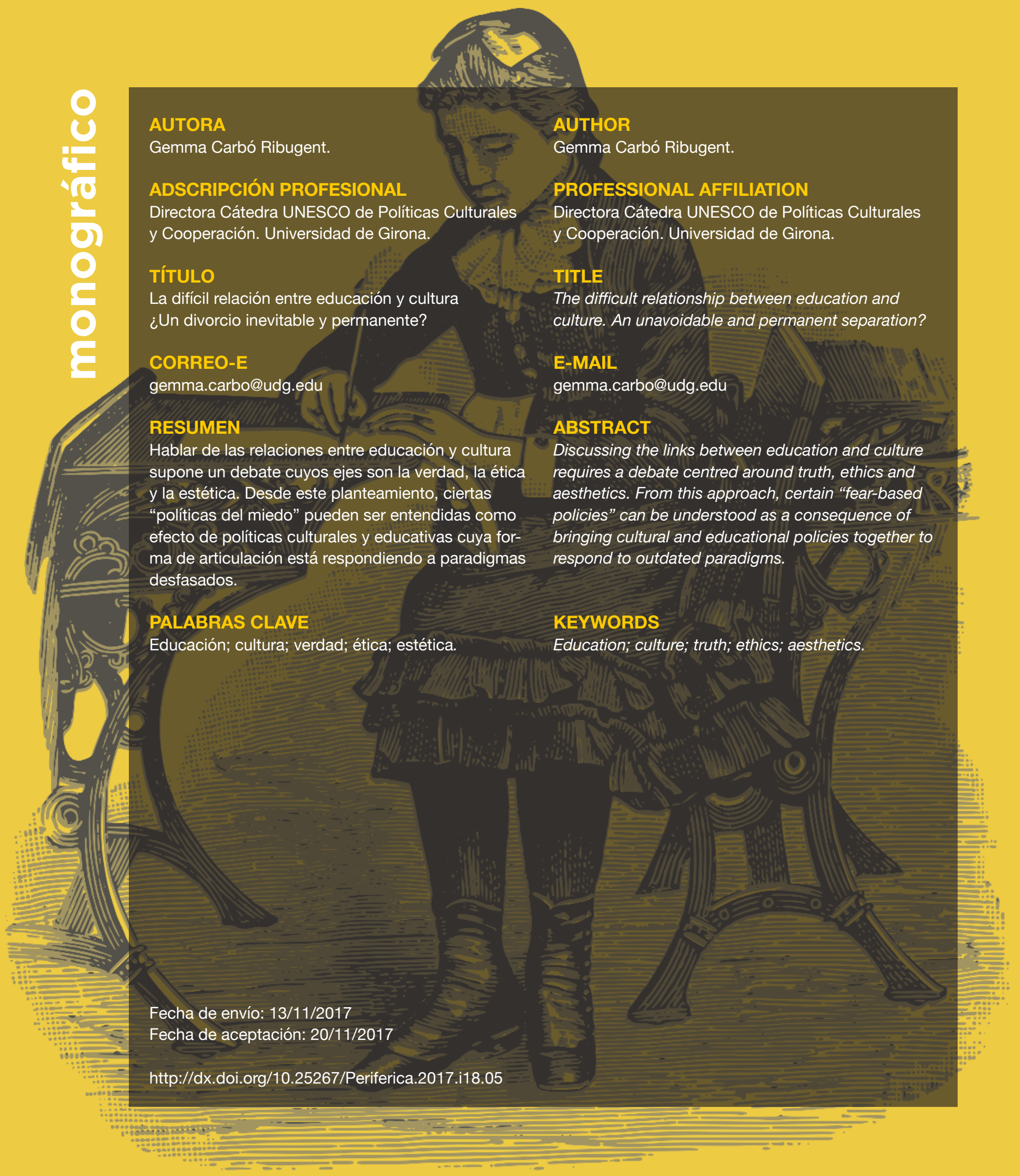




\section{La difícil relación entre educación y cultura. ¿Un divorcio inevitable y permanente? Gemma Carbó Ribugent}

No es la ley, sino la educación y la costumbre, lo que produce la diferencia

(Taylor, 1973: 95)

La intolerancia estética tiene violencias terribles

(Bourdieu, 2016: 55)

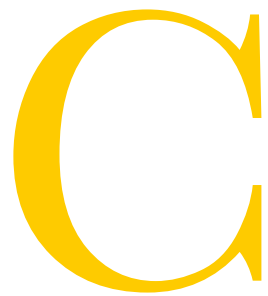

uando hablamos de las relaciones entre educación y cultura nos situamos ciertamente frente a un debate permanente y una problemática histórica en España ${ }^{1}$ y probablemente en el resto del mundo. En este debate, nuestra posición desde las ideas, las políticas y las prácticas vendrá condicionada por la relación que establezcamos entre, justamente, los tres conceptos que articulan este monográfico: la verdad, la ética y la estética.

En este artículo, partimos de la siguiente hipótesis: en buena medida, el auge de los populismos, de los nacionalismos, de los fundamentalismos, de la violencia de género y de la posverdad, aspectos todos ellos fundamentados en las estrategias del miedo y que no son exclusivos de nuestra época, puede entenderse como efecto de políticas culturales y educativas cuya forma de articulación está respondiendo a paradigmas desfasados.

La pedagogía primero y la sociología contemporánea después han tratado de analizar la cuestión desde distintas perspectivas pero todas ellas coinciden en señalar que la forma específica de relación entre ambos campos da lugar a, y/o se fundamenta en, una política pública determinada.
Eulalia Bosch en su libro Educación y vida cotidiana nos introduce el debate con esta afirmación: “(...) cultura general, francés y piano definían perfectamente en la España de la postguerra una perspectiva educativa diseñada a medida del futuro que se deseaba para las niñas-mujeres conquistadas por sus maridos como un objeto más de representación" (Bosch, 2003: 35).

Si nos situamos en el contexto actual, podríamos decir que el management, el inglés y la informática son la nueva perspectiva educativa para mujeres elegantes como elemento atractivo en los niveles -siempre intermedios-de dirección.

Lo que queremos señalar con esta introducción es que nuestra posición en el debate se podría resumir en una ecuación fundamental: defendemos la educación como garantía de emancipación y participación en la vida cultural y ello implica repensar el vínculo educación-cultura en términos de desigualdad social, cuestiones de género y de otras luchas culturales contemporáneas.

Desde la perspectiva sociológica, la distinción social según Bourdieu (2016) ha venido dada históricamente por la rentabilidad cultural que permite el control del capital económico y cultural por parte de determinados entornos familiares. En el otro extremo, las clases populares, en 
oposición a la cultura hegemónica reivindican sus propias prácticas culturales, de carácter pragmático, entendidas a menudo como servicio comunitario y basadas según Bourdieu (2016) en la defensa de los valores tradicionales en oposición a las vanguardias. Alta cultura frente a cultura popular como primer anatema; modernidad y tradición como cuestión que afecta especialmente a las relaciones de género y que está presente, a nuestro modo de ver, en todas las formas culturales.

Las sociedades del bienestar de mediados de siglo XX permitieron la generalización en nuestro país de una clase media que multiplicó exponencialmente la demanda de acceso a esta cultura dominante esencialmente masculina con la que no existía una familiaridad adquirida. Esta clase media incluía a la mujer como sujeto político en mayor o menor medida. La expectativa estaba puesta por ello, en los sistemas educativos como garantes del ascensor social y de la igualdad de género. La escuela pública y la aparición de los ministerios de cultura intentaron responder históricamente a estos retos hasta finales del siglo XX pero la crisis contemporánea del estado del bienestar derivada de la globalización económica y social ha abierto de nuevo la caja de Pandora generando la necesidad de una revisión del debate educativo-cultural que es, al fin, un debate ético-político.

\section{Los ministerios de cultura y las políticas cultura- les-educativas: perspectiva histórica \\ Los estados nación modernos asumieron desde finales} del siglo XVIII la tarea educativa y cultural como misión claramente orientada a posibilitar el acceso a la cultura legítima concretada en las bellas artes, la creación de los grandes museos nacionales y la protección de la industria editorial principalmente. Para ello se impulsó la creación de los sistemas públicos de educación y las universidades.

En el siglo XIX la política cultural seguirá directamente vinculada a la instrucción pública. El movimiento romántico europeo denunciará la burocracia cultural del buen gusto y exigirá la incorporación del pueblo y su cultura popular, el folklore en la configuración de los nuevos escenarios. La hibridación entre las distintas formas culturales y clases sociales, el crecimiento de la clase media, unida al desarrollo de los medios de comunicación darán paso a una nueva cultura de masas cuyo máximo exponente será la propaganda como sistema de control cultural-educativo eficazmente utilizado por parte de los regímenes totalitarios en la primera mitad el siglo XX.
Si nos centramos en España, el primer intento efectivo de acción legislativa en materia de educación y cultura es la Ley Moyano de Instrucción pública de 1857 (Puelles, 1999). En 1879 nace el primer partido socialista con un proyecto educativo heredero del liberalismo y en este período, el anarquismo reivindica también su apuesta por la educación popular a través de los ateneos y escuelas de barrio.

En 1900 se crea el primer Ministerio de Instrucción Pública en España y en 1901 Francesc Ferrer funda la Escuela Moderna inspirándose en Rousseau y apostando por el contacto del niño con la naturaleza y la cultura entendida como el entorno social: fábricas e instituciones sociales-artísticas. En Cataluña en 1915 se constituía la Dirección General de Bellas Artes y Prat de la Riba impulsaba la normalización linguística, la educación profesional y artística, las escuelas de profesores y la red de bibliotecas públicas, museos y patrimonio o la creación de academias científicas y de las artes. La actuación pública en materia cultural y educativa era urgente porque los índices de analfabetismo rondaban las tasas del 50\% (Puelles, 1999).

La guerra civil y el franquismo frenan esta evolución. Intelectuales y profesores deberán exiliarse o someterse a depuración ideológica (Marquès y Portell, 2006). La educación deja de suponer una oportunidad de ascenso social para convertirse en espacio de adoctrinamiento y transmisión de unos valores nacionales y religiosos esenciales: por dios y por la patria. El Ministerio de Instrucción Pública y Bellas Artes pasa a denominarse Ministerio de Educación Nacional. Las leyes universitarias (1943) y educativas (1945) confirman la entrega definitiva de la educación a la iglesia y al régimen.

En Europa, después de la $2^{a}$ guerra mundial, los estados incorporarán la cultura a las políticas públicas centrándose aún en la gestión del patrimonio cultural y las bellas artes pero habiendo entendido también la necesidad de cubrir el déficit de participación social y privada en momentos de descolonización y crisis de la cultura tradicional en el contexto de la construcción del estado del bienestar. La apuesta por la cultura como espacio de participación y libertad también para las clases trabajadoras pretendía frenar la seducción del comunismo.

En este contexto como es bien sabido, nacen las primeras políticas culturales institucionalizadas a partir de 1959 en Francia y con ellas el primer paradigma de la democratización cultural, el de la animación sociocultural (Rius, 2004) como tendencia que busca poner en diálogo realidades culturales hegemónicas con aquellas surgidas de la generalización de los mass media y la reproducción en serie de la obra de arte, largamente denunciada por la escuela de Frankfurt. 
El movimiento romántico

\section{europeo denunciará}

\section{la burocracia cultural}

del buen gusto y exigirá

la incorporación del pueblo

y su cultura popular, el

folklore en la configuración

de los nuevos escenarios.

En España el paréntesis largo del franquismo dibuja un especial retrato de este paradigma hasta la recuperación de los gobiernos democráticos en los años 80. Como en todos los regímenes totalitarios, la cultura y la educación cumplieron un rol esencial desde una forma específica de articulación.

En materia educativa, consciente de que la estrategia de control de las clases populares pasaba pese a todo por garantizar una cierta alfabetización que diera acceso al mercado de trabajo, el régimen promueve en el año 1959 la Ley sobre Universidades Laborales pero se enfrenta permanentemente a un entorno universitario donde los pocos intelectuales no exiliados resisten y en 1965 lideran la oposición al régimen cuando las huelgas y las manifestaciones terminan con la expulsión, entre otros, del catedrático de ética José Luis López Aranguren a la que sigue la renuncia de su discípulo José María Valverde, catedrático de estética, con una famosa sentencia que resumía la situación en España: no hay ética sin estética.

En 1965, una cierta apertura derivada del desarrollismo permitió que en el ámbito educativo se creara en Cata- lunya la asociación de renovación pedagógica Rosa Sensat y que en 1970 se promoviera la Ley General de Educación, o Ley Villar, que representa un primer intento por modernizar las caducas estructuras educativas del régimen con el asesoramiento de los técnicos de la UNESCO.

En el ámbito cultural, el régimen del general Franco apuesta en 1952 por la entrada a la UNESCO, no exenta de notables críticas de la izquierda exiliada. El gran interés del gobierno franquista era participar en la conferencia sobre derechos de autor de la que surgió la primera gran convención en esta materia ${ }^{2}$. La protección de la producción literaria propia en lengua castellana era ahora el nuevo objetivo de las políticas culturales. En paralelo, las Bellas Artes configuraron una dirección general del Ministerio de Instrucción pública durante todo el período integrando en su concepto una mezcolanza de oferta cultural estratégicamente dirigida a los distintos sectores y al servicio esencialmente de la generación de identidad nacional entendida como fundamento educativo y como producto de consumo para los turistas. No será hasta la recuperación de la democracia cuando se crea en España el primer Ministerio de Cultura de su historia (Decreto 2258/77 de 27 de agosto).

Según Badia y Marzo ${ }^{3}$, entre 1985 y 2005, en términos de políticas culturales se siguió en España la consigna internacional de la democratización cultural del estado del bienestar sin asegurar sin embargo una política educativa de base ni las relaciones y vínculos con la universidad. El despliegue de competencias autonómicas implicó un proceso de descentralización que generó, en Cataluña, la reaparición de la narrativa nacionalista catalana basada según estos autores en una (...) "política cultural de mínimos entre el neoliberalismo y el paternalismo, basada en criterios de clase y de identidad".

Ya en el siglo XXI la situación viene caracterizada por la crisis económica y estructural de este estado del bienestar, la comercialización del ocio y la generalización de las industrias culturales. Fruto de las políticas anteriores, la crisis destapa actitudes de nuevo polarizadas evidenciadas en discursos xenófobos contra la inmigración, en la reaparición de los viejos nacionalismos y en el consumismo individualista que afecta drásticamente las formas de participar en la vida cultural. Los modelos educativos se cuestionan a sí mismos e intentan buscar soluciones a las altas tasas de fracaso y abandono escolar, a la radicalización de sus jóvenes ${ }^{4}$ y a un modelo cultural de convivencia que parece haber caducado ${ }^{5}$.

En términos de paradigmas políticos parecería según Miralles (2007: 5) que nos situamos hoy en el denominado 
estado relacional basado en la democracia cultural como consigna frente a estos retos junto con una educación integral y por competencias que debería permitir la superación de las tradicionales formas de relación educación-cultura.

Para hacerlo posible necesitamos sin embargo, analizar a fondo los espacios de tensión que hemos generado entre las dos políticas públicas más relevantes para nuestra supervivencia como especie y como sociedad.

\section{Encuentros y desencuentros}

En la investigación realizada para entender estos encuentros y desencuentros en el contexto específico de Cataluña, se analizaron los prólogos de cerca de 200 leyes de educación y cultura promulgadas por el parlamento español y catalán entre 1980 y 2010 identificando los puntos de convergencia y divergencia entre ellos. Estos resultados se contrastaron después con entrevistas realizadas a 18 expertos y

\begin{tabular}{|c|c|c|c|c|c|}
\hline $\begin{array}{c}\text { Forma } \\
\text { de estado }\end{array}$ & $\begin{array}{c}\text { Política } \\
\text { educativa }\end{array}$ & $\begin{array}{c}\text { Política } \\
\text { cultural } \\
\text { Estado } \\
\text { moderno }\end{array}$ & $\begin{array}{c}\text { Instrucción } \\
\text { pública }\end{array}$ & $\begin{array}{c}\text { Estrategias } \\
\text { básicas } \\
\text { patrimonial } \\
\text { de intervención }\end{array}$ & $\begin{array}{c}\text { Grados } \\
\text { de relación }\end{array}$ \\
\hline $\begin{array}{c}\text { Estado } \\
\text { del bienestar }\end{array}$ & $\begin{array}{c}\text { Formación } \\
\text { permanente }\end{array}$ & $\begin{array}{c}\text { Democratización } \\
\text { de la cultura }\end{array}$ & $\begin{array}{c}\text { Servicio } \\
\text { público } \\
\text { (rendimiento) }\end{array}$ & $\begin{array}{c}\text { Eficacia } \\
\text { (objetivos) }\end{array}$ & Colaboración \\
(recurso) \\
\hline $\begin{array}{c}\text { Estado } \\
\text { relacional }\end{array}$ & $\begin{array}{c}\text { Educación } \\
\text { integral }\end{array}$ & $\begin{array}{c}\text { Democracia } \\
\text { cultural }\end{array}$ & Fomento & $\begin{array}{c}\text { Efectividad } \\
\text { (impacto) }\end{array}$ & Competencia \\
(se solapan)
\end{tabular}

Fuente: E. Miralles (Xabide, 2007: 5).

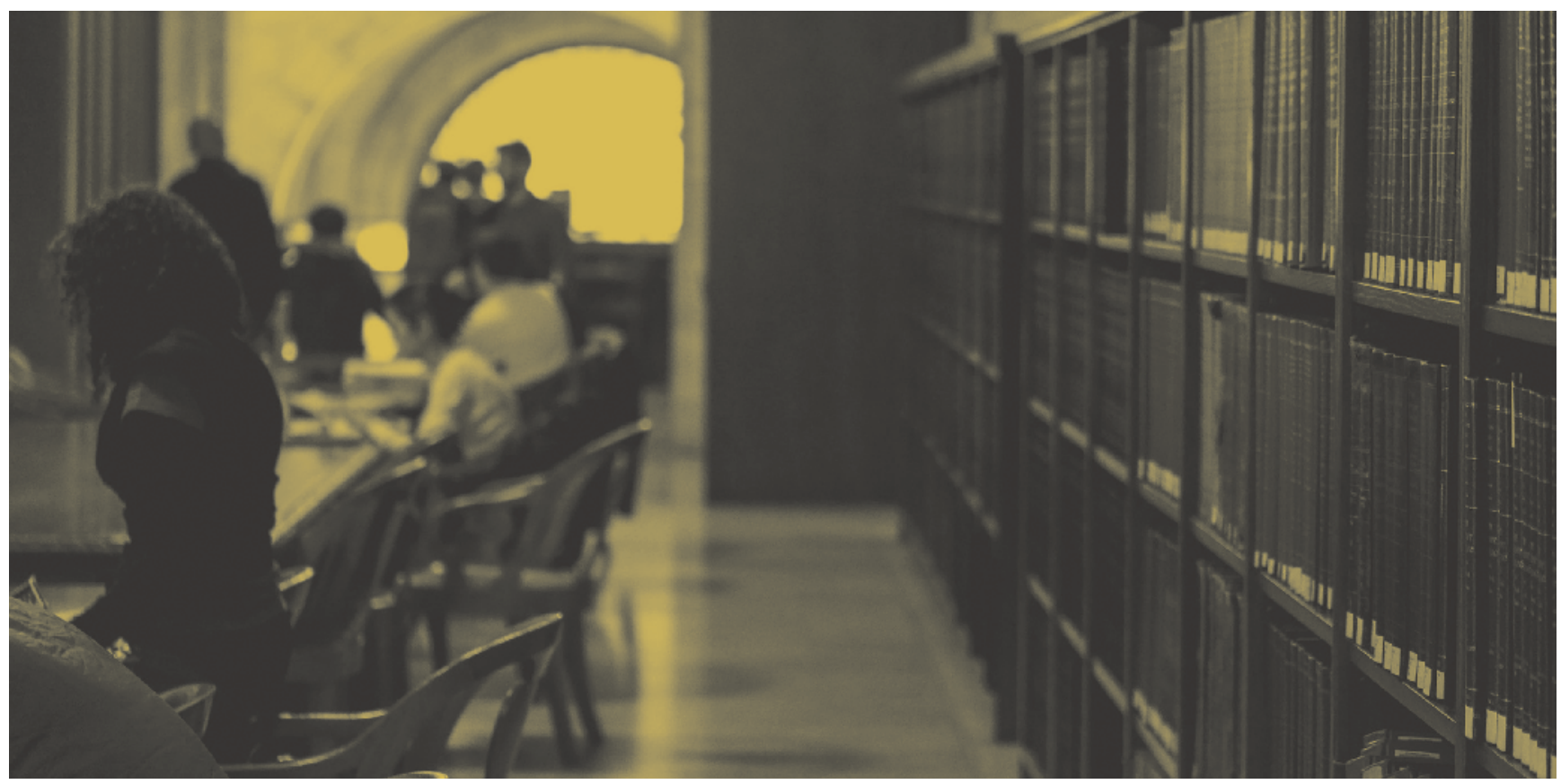


expertas internacionales y locales. Todo ello permitió establecer de forma sistemática algunas categorías conceptuales que explican los factores de divergencia

La burocracia y la complejidad de la administración pública constituyen el primer obstáculo evidente para una coordinación eficaz entre ambos sectores. Esta división administrativa no explicaría por si sola la distancia o el acercamiento en la relación entre políticas culturales y educativas pero si evidenciaría una forma de entender su orientación.

En España hubo Ministerio de Cultura entre 1977 y hasta 1996. Entre 1996 y 2004 se fusionó con el de Educación (y deporte). Tras las elecciones generales de 2004, se volvió a crear un Ministerio de Cultura diferenciado de Educación y, finalmente, en la X Legislatura, desde el 22 de diciembre de 2011, el Ministerio de Cultura desaparece con esta denominación y sus competencias son recogidas de nuevo por el Ministerio de Educación, Cultura y Deporte.

De acuerdo con la opinión de los expertos/as entrevistados, el problema de fondo radicaría en la tradición política. Una tradición que a principios de siglo XX estaba vinculada aún con la filosofía y la pedagogía, con la cultura y la educación pero cuya tendencia contemporánea es a confundir política con administración y programas con departamentos.

La complejidad administrativa en España no solo viene dada por la existencia de ministerios separados o de direcciones generales de cultura supeditadas a los ministerios de educación sino también por la organización territorial planteada en 1978. Las comunidades autónomas, las diputaciones provinciales, los consejos comarcales y los ayuntamientos son los distintos niveles del estado con competencias en materia de cultura y/o educación.

La distribución competencial ha sido objeto de debate e interpretación constitucional en todo momento no solo entre Estado y autonomías sin también, de forma más reciente, entre Estado y gobiernos locales que han visto recortadas sus competencias de forma importante con la última ley de Régimen Local cuando son en realidad el nivel político que más invierte en cultura.

En todos los niveles administrativos, la lógica es departamental y las áreas están compartimentadas generando división de responsabilidades, gestión especializada y desconexiones abrumadoras que se concretan en la realización por ejemplo, de planes estratégicos paralelos para el ámbito cultural y el educativo que buscan en definitiva resolver las mismas problemáticas o en la negativa constante a la concesión de ayudas y subvenciones a proyectos transversales argumentando que son de "educación" o son de "cultura".
Otros ámbitos de desencuentro importantes han sido los generados por la profesionalización de la gestión cultural. La formación en este campo ha sido heredera de la división administrativa y competencial y ha renunciado a considerar la educación como una línea de trabajo específica del gestor cultural. El mundo educativo ha sido visto por los gestores culturales como un espacio de transmisión pautada de conocimientos claramente desvinculados de la actividad cultural contemporánea y las dinámicas expresivo-creativas.

En el entorno cultural, el sistema educativo es percibido como un entorno conservador por naturaleza, de carácter universal y generalista que aboga por una igualdad homogeneizadora y que se ha ido alejando de la visión integral del ser humano para centrarse únicamente en la formación para la inserción en el mercado laboral con resultados cada vez más discutibles.

En paralelo, profesoras y maestros ha ido constatando como, de forma progresiva, la función educativa de los espacios culturales se convertía en una oferta comercial orientada a la creación de públicos escolares que suplieran la falta de consumo cultural en los días lectivos. Tal vez la mejor expresión de todo ello la tengamos en los medios de comunicación y en el carácter estereotipado de las noticias sobre el mundo educativo que aparecen siempre en espacios de sociedad y desde una visión negativa que incide en las problemáticas, mientras que la cultura ocupa los espacios de espectáculos y ocio, de reconocimiento y aparente relevancia social.

De acuerdo con el estudio citado, la punta de la pirámide de la desconexión entre ambos mundos se sitúa en una universidad que ha ido renunciando de forma progresiva a su tradición humanista y su apuesta por la extensión cultural para centrarse en los discursos de la eficacia, la innovación y la formación de profesionales, profesores y actores culturales, preparados para la competitividad científica y tecnológica pero cada vez menos, para entender el mundo complejo en el que vivimos. Muchas son las voces que se han alzado frente a esta cuestión. Baste recordar el discurso de Martha Nussbaum en la Universidad de Antioquia ${ }^{6}$ : “(...) Si no insistimos en la importancia crucial de las humanidades y las artes, éstas se desplomarán, porque no generan dinero. Sólo hacen algo que es mucho más valioso que eso, hacen un mundo en el que vale la pena vivir, las personas que son capaces de ver a otros seres humanos como personas llenas, con pensamientos y sentimientos propios que merecen respeto y simpatía, y naciones que son capaces de superar el miedo y la sospecha en favor del debate comprensivo y motivado". 
Por último, pero no por ello menos importante, el estudio apunta otros dos factores que explicarían el divorcio educación y cultura. El primero, la revolución digital, vivida como una oportunidad para el mundo de las artes y como un gran problema para el sector educativo. El segundo, la implosión de una realidad cotidiana diversa en sus formas culturales y expresivas en aulas y espacios públicos donde no se había resuelto la cuestión de las identidades. Una y otra cuestión están, de facto, intrínsecamente relacionadas y han generado el gran cambio de paradigma cultural que ni la escuela, ni la gestión cultural no sabe aún como afrontar.

\section{Diversidad cultural: el gran reto cultural-educati- vo contemporáneo}

El paradigma de la diversidad cultural es algo novedoso en el discurso de las políticas culturales nacionales que siempre se han mostrado reticentes a su aceptación, tal vez por estar demasiado ligada, según su visión restringida, a los derechos de autodeterminación y los nacionalismos.

También en Europa, la diversidad cultural ha sido y sigue estando relacionada con el conflicto y la violencia vinculada al poder. La diferencia no es un aspecto a considerar por los estados nación de carácter centralista y aparentemente mono-culturales hasta finales de siglo XX, momento en que la situación empieza a cambiar. Como señala Patricio Rivas (Rivas, 2011) “... Paulatinamente, los territorios de lo diverso, que se vincularon en su cierne a temas étnicos y la lucha por los derechos civiles, comienzan a ampliar sus actores, enfoques y tramas. Irrumpe una múltiple polifonía de diversidades: los temas de género, jóvenes, mundos urbanos, la re-emergencia de lo local, medio ambiente, biodiversidad, las nuevas estéticas, dando lugar así, a un giro en la noción política, intelectual y ética de la diversidad cultural..."7.

La diversidad cultural resume pues como concepto los anatemas de la lucha de clases ampliados con las luchas culturales contemporáneas entre las cuáles, la de género. Por ello tornase un elemento central en las relaciones internacionales a partir de 1998 y 2001 con el Informe Mundial Nuestra Diversidad Creativa y en especial a partir de 2005 año de la aprobación de la Convención UNESCO para la Protección y Promoción de la Diversidad de las Expresiones Gulturales. De acuerdo con esta convención, la diversidad de expresiones culturales "constituye hoy un patrimonio común de la humanidad. Es para el género humano, tan necesaria como la diversidad biológica para los organismos vivos.
Constituye un factor de desarrollo en términos económicos" por ser el fundamento de la economía creativa y una vía de acceso a una existencia satisfactoria (UNESCO, 2005).

Ha sido, como señala Yúdice (2002), constatar que estas expresiones vinculadas al potencial del mundo digital constituyen un gran recurso económico y articulan un sector estratégico que configuran las industrias culturales y creativas, el detonante para la reacción política internacional. La diversidad cultural resulta ser la condición para la creatividad y la innovación para formas de pensamiento lateral e interdisciplinar indispensables en los nuevos contextos económicos y sociales. Garantiza la aportación de contenidos originales a las industrias de la información y la comunicación y añade valor a los equipos de trabajo e investigación. La revolución digital vinculada a esta diversidad cultural pone en entredicho las formas de lucha convencionales: “... con la generalización de los bienes y servicios culturales, el hecho cultural pierde el carácter presencial que lo hacía históricamente elitista. El núcleo ineludible de su negocio consiste en transformar en contenidos culturales, "valores simbólicos" en valor económico" (Rey, 2009).

Por todo ello, desde la excepción cultural propuesta por Francia y Canadá en la década de los noventa hasta la rápida ratificación de la convención de 2005 han pasado pocos años y la reacción política internacional ha sido la más significativa en la historia de la política cultural global.

Pero entender la defensa de esta diversidad únicamente desde la perspectiva económica sería un grave error que algunas voces entre los organismos internacionales han tratado de evitar en el proceso de impulso a la convención. Las lecturas integrales a la diversidad como principio defienden que la cultura política de su defensa es aquella que se fundamenta en la participación de la ciudadanía en el espacio público. La persona, más allá de sus raíces nacionales, étnicas, religiosas o culturales es miembro de una comunidad política y acepta voluntariamente un vínculo social con derechos y obligaciones. Esta perspectiva implicaría la renuncia a toda actitud fundamentalista que quisiera imponer los referentes culturales y morales de una determinada comunidad como obligatorios.

Todos aquellos factores culturales que atentan contra la dignidad humana no pueden ser considerados como positivos en nombre de la diversidad, la libertad se concreta en la libertad de opción y expresión de visiones y percepciones del mundo que pueden ser individuales o colectivas y que se transmiten a través de diferentes lenguajes y formas de saberes locales que implican riqueza global. 
Dicho de otra manera y en relación al tema propuesto por este monográfico, la defensa de la diversidad no puede limitarse a una cuestión estética (diversidad de expresiones artísticas y culturales) sino que debe implicar un compromiso ético con los portadores/as de la expresividad creativa que incluya la garantía de su propiedad intelectual y la protección de sus derechos fundamentales a la participación, la libertad de expresión y la información. Si volvemos al tema que nos ocupa, todo ello afecta directamente a los modos de entender hoy el papel de las artes y la cultura en la educación.

\section{Hacia una educación artística crítica e intercultural}

Frente a esta nueva realidad a la que la escuela y la educación hoy se enfrentan, la pedagogía crítica se vuelve intercultural y aboga por cambios significativos no solo en los contenidos y en las formas y usos escolares (a menudo alejados de las prácticas participativas y democráticas), sino también en la propia estructura educativa que debería fundamentarse en estas identidades culturales diversas entendidas como procesos continuados, individuales y colectivos de construcción de ciudadanía no solo en la educación formal, sino también en la no formal, la informal y en definitiva, a lo largo de toda la vida. Como señala Edgar Morin: “... Tenemos que enseñar no a oponer lo universal a las patrias sino a vincular concéntricamente nuestras patrias, familiares, regionales, nacionales, europeas y a integrarlas en el universo concreto de la patria terrestre. Todas las culturas tiene sus virtudes y experiencias, sus saberes, a la vez que sus carencias y sus ignorancias" (Morin, 2000).

En el discurso educativo, como en el discurso del desarrollo, hemos asumido que la clave para esta nueva formación humanística radica en el objetivo de formar personas competentes o con grandes capacidades. Desde una visión que nos parece aún un poco sesgada, el discurso de las competencias educativas en Europa y en España apuesta por la transversalidad del hecho cultural y comunicativo aunque sigue poniendo demasiado el acento exclusivamente en la competencia digital.

A nuestro modo de ver, la competencia digital, el conocimiento y uso de estas tecnologías es fundamental para la promoción de la diversidad cultural sin duda alguna, pero siempre buscando la complementariedad con competencias que parecen mucho más vitales. Marta Nussbaum (1995) menciona en especial dos competencias que han sido recogidas por los programas de Educación para el Desarrollo por su especial significación, son las competencias conocidas como "imaginación narrativa" y "cosmopolitismo" directamente vinculadas al diálogo intercultural y la construcción de la paz, requisito indispensable para la protección de la diversidad de expresiones culturales.

La imaginación narrativa es aquella capacidad receptiva que permite la adquisición de valores y principios morales, una capacidad que desarrolla el niño o niña desde el momento en que los adultos empiezan a contarle historias a través de las canciones, los movimientos y los lenguajes maternos, simbólicos y/o artísticos. Las artes, la narración, generan esta habilidad de reconocerse a uno mismo en los personajes y reconocer a los otros en las emociones, gustos, necesidades y sentimientos.

Esta imaginación narrativa es la que conduce sin duda, al ideal cosmopolita, al compromiso con la comunidad de los seres humanos, a la consideración de la unidad en la diversidad, conocimiento básico de la educación del futuro como señala Edgar Morín (2007). Marta Nussbaum (1995) opina en este sentido, y compartimos con ella la visión, que los partidarios del nacionalismo político y educativo acostumbran a hacer una débil concesión al cosmopolitismo cuando en realidad la educación cosmopolita nos permite aprender más acerca de nosotros mismos, avanzar resolviendo problemas que requieren la cooperación internacional, reconocer obligaciones morales con el resto del mundo que son reales, elaborar argumentos sólidos y coherentes basados en las distinciones que estamos dispuestos a defender. "Si no logramos educar a los niños para que puedan traspasar las fronteras con su mente y su imaginación, tácitamente les estaremos dando el mensaje de que, en realidad, no creemos lo que les estamos diciendo" (Nussbaum, 1996: 22-26).

De la educación por competencias se derivan cuestiones pragmáticas y por ello difíciles que implican resolver la integración de la diversidad en los programas escolares de acuerdo con los contextos sociales, la revisión de los materiales pedagógicos y educativos bajo los paradigmas culturales contemporáneos (género, medioambiente etc.), la implicación de los artistas y creadores en los procesos formativos, la consideración del patrimonio cultural como gran recurso educativo, la formación de formadores y gestores culturales preparados para esta transversalidad, la creación de públicos participativos, la educación de consumidores críticos, la formación de ciudadanía cultural en definitiva, para el siglo XXI.

\section{A modo de conclusión}

Es justamente desde esta nueva visión sobre lo que significa educar hoy desde donde urge reclamar al sector cultural su compromiso político y social. La participación en 
la vida cultural es un derecho fundamental reconocido en el PIDESC y cada vez más jurídicamente articulado debido a los informes y documentos impulsados por Naciones Unidas y las relatoras especiales para los derechos culturales. Entre ellos, la observación general n ${ }^{\circ} 21$ (CESCR 2009) señalaba en su momento que esta participación se concreta no solo en la posibilidad de elegir o acceder sino en especial, de contribuir.

Para facilitar el contribuir a la vida cultural será necesario que los gestores y políticas culturales se centren en este desarrollo de capacidades y competencias, en facilitar la práctica efectiva del teatro, la música, la danza, la poesía, las artes en general. No se trata de convertir los centros culturales en centros educativos pero si de establecer las alianzas entre ambos para permitir el intercambio de profesionales y un uso efectivamente público de los espacios físicos y virtuales así como una participación efectiva de toda la ciudadanía en las programaciones y decisiones de la escuela y de los centros culturales.

Los proyectos innovadores en este sentido son cada vez más numerosos e incluyen residencias artísticas en centros escolares, tándems entre centros culturales y educativos o apuestas por el trabajo combinado artista-profesor para la renovación de las formas de enseñar y aprender. Especialmente destacables son las pedagogías del cuerpo, la danza y las artes escénicas, con poca o nula presencia hasta hoy en los currículos escolares y sin embargo, altamente demandadas como competencias clave en la actualidad.

En el ámbito de la música y las artes visuales, a pesar de que su presencia en el contexto escolar había logrado algunos niveles aceptables antes de la última reforma educativa de la LOMCE, la vinculación directa entre el mundo artístico profesional y la pedagógica crítica está garantizando un nuevo enfoque que pone el acento en la posibilidad del trabajo artístico colectivo (orquestras escolares, arte comunitario etc.) donde se vincula lo estético con lo ético.

A modo de conclusión señalar que es urgente asumir el reto educativo en las políticas y la gestión cultural y el reto de la formación estética y cultural en los espacios educativos siendo conscientes del potencial emancipador o, como señalábamos al inicio, adoctrinador que esta alianza puede tener. Para ello, los actores culturales y educativos deberían especificar de forma clara en sus códigos éticos los principios que fundamentan su acción y que a nuestro modo de ver no pueden ser otros que la democracia y la convivencia pacífica a partir del diálogo estético e intercultural que las artes y la cultura posibilitan.

\section{NOTAS}

(1) Núria Espert: «la educación "es el gran problema de este país". En un país "no culto", como España, "los políticos tienen tiempo para hablar de todo menos de cultura y solo de pasada, de la educación"». http://www.elmundo. es/cultura/2016/10/21/58096196468aebd35f8b45d8.html

(2) La Convención Universal sobre los Derechos de Autor se adoptó bajo los auspicios de la UNESCO en 1952.

(3) MARZO Y BADIA (2006), Las políticas culturales en el Estado Español (1985-2005). Consulta en: www.soymenos. net/politica_espanya.pdf.

http://www.elmundo.es/cataluna/2017/08/22/599c06dde5fdea79738b459e.html

(5) http://www.huffingtonpost.es/2017/09/12/ los-catalanes-menores-de-35-anos-son-mas-independentistas-que-sus-mayores_a_23205466/

(6) https://www.elheraldo.co/educacion/el-durodiscurso-de-martha-nussbaum-sobre-el-futuro-de-la-educacion-mundial-233416

(7) RevistaWale'keru de investigación en cultura y desarrollo, $\mathrm{n}^{\circ}$ 1. http://www.walekeru.net. Fecha última consulta: octubre 2017

\section{BIBLIOGRAFÍA}

BOSCH, E. (2003). Educació $i$ vida quotidiana : Històries breus de llarga durada, Vic, Eumo.

BOURDIEU, P. (1998). La distinción. Criterio y bases sociales del gusto, Madrid, Taurus.

CESCR (2009). Observación general no 21 Derecho de toda persona a participar en la vida cultural. Ginebra

MILL, M. and TAYLOR, H. (1973). Ensayos sobre la igualdad sexual, Barcelona, Península.

MIRALLES, E. (2007). "Cultura y educación, ¿una extraña pareja?" en R. Gómez de la Iglesia, Acción pedagógica en organizaciones artísticas y culturales, Grupo Xabide, Vitoria-Gasteiz.

MORIN, E. (2000). Els 7 coneixements necessaris per a l'educació del futur [Les sept savoirs nécessaires à l'éducation du futur] (H. Cots Trans.), Centre UNESCO de Catalunya, Barcelona.

NUSSBAUM, M. (1995). Poetic justice. The Literary Imagination and Public Life, Beacon Press, Boston.

NUSSBAUM, M. (2010). Sin fines de lucro. Por qué la democracia necesita de las humanidades, Katz Editores, Madrid-Buenos Aires. 
NUSSBAUM, M. and COHEN, J. (eds.) (1996). For love of country: Debating the limits of patriotism, Beacon Press, Boston.

PUELLES BENÍTEZ, M. (1999). Educación e ideología en la España contemporánea (4 ${ }^{\mathrm{a}}$ ed.), Editorial Tecnos, Madrid.

REY, G. (2009). Industrias culturales, creatividad y desarrollo, Agencia Española de Cooperación Internacional para el Desarrollo, Madrid.

RIUS, J. (2004). Un nou paradigma de la politica cultural: Estudi sociològic del cas barceloní, Univertat Autònoma de Barcelona, Barcelona.
UNESCO (2005). Convención sobre la protección y promoción de la Diversidad de expresiones culturales, http:/ / unesdoc.unesco.org/images/0014/001429/142919s.pdf

YÚDICE, G. (2002). El recurso de la cultura: Usos de la cultura en la era global ( $1^{\text {a }}$ ed.), Editorial Gedisa, S. A., Barcelona. 